\title{
Who Is Conducting "Better" Employment Interviews? Antecedents of Structured Interview Components Use
}

\author{
Nicolas Roulin \\ Saint Mary's University \\ Joshua S. Bourdage \\ University of Calgary \\ Timothy G. Wingate \\ University of Calgary
}

Follow this and additional works at: https://scholarworks.bgsu.edu/pad

Part of the Human Resources Management Commons, Industrial and Organizational Psychology Commons, and the Other Psychology Commons

How does access to this work benefit you? Let us know!

\section{Recommended Citation}

Roulin, Nicolas; Bourdage, Joshua S.; and Wingate, Timothy G. (2019) "Who Is Conducting "Better" Employment Interviews? Antecedents of Structured Interview Components Use," Personnel Assessment and Decisions: Number 5 : Iss. 1 , Article 2.

DOI: https://doi.org/10.25035/pad.2019.01.002

Available at: https://scholarworks.bgsu.edu/pad/vol5/iss1/2

This Main Article is brought to you for free and open access by the Journals at ScholarWorks@BGSU. It has been accepted for inclusion in Personnel Assessment and Decisions by an authorized editor of ScholarWorks@BGSU. 


\title{
Who Is Conducting "Better" Employment INTERVIEWS? ANTECEDENTS OF StRUCtURED INTERVIEW COMPONENTS USE
}

\author{
Nicolas Roulin ${ }^{1}$, Joshua S. Bourdage ${ }^{2}$, and Timothy G. Wingate ${ }^{2}$ \\ 1. Saint Mary's University \\ 2. University of Calgary
}

\section{KEYWORDS}

structured interview, individual differences, personality
ABSTRACT

\begin{abstract}
The employment interview remains a unique paradox. One the one hand, decades of research demonstrates that using more structured components (e.g., question consistency, evaluation standardization) can largely improve the psychometric properties of interviews. On the other hand, although interviews are almost universally used, many interviewers still resist using structured formats. We examined the use of seven structure components by 131 professional interviewers and their association with three types of antecedents: interviewers' background (e.g., experience, training), the focus of the interview (selection vs. recruitment), and interviewers' personality (based on the HEXACO model). Interviewers' background (i.e., training) and the focus of the interview were largely associated with the use of question sophistication, question consistency, note taking, and evaluation standardization. Personality (i.e., extraversion) was mostly associated with rapport building and probing. Our findings highlight the importance of providing formal training to interviewers but suggest that attempting to eliminate less-structured components could encounter resistance from some interviewers.
\end{abstract}

The concept of interview structure and how it can improve the psychometric properties of employment interviews has been discussed in selection research for over 30 years (Campion, Palmer, \& Campion, 1997; Campion, Pursell, \& Brown, 1988; Levashina, Hartwell, Morgeson, \& Campion, 2014). Structuring an interview can involve several components, including asking questions in a consistent way, asking "better" or more sophisticated questions, taking descriptive notes, limiting probing or rapport building, and standardizing the evaluation (Chapman \& Zweig, 2005; Huffcutt \& Arthur, 1994; Levashina et al., 2014). However, the structured interview is often described as a prime example of the academic-practitioner gap, because despite its advantages, many interviewers still prefer to rely on less-structured approaches (Lievens \& De Paepe, 2004; Ryan, McFarland, Baron, \& Page, 1999).

There are a number of reasons why interviewers may refrain from using structured interviews, including interviewers' needs to establish an informal contact with interviewees or have discretion over interview questions (Lievens \& De Paepe, 2004), subjective norms about structured versus unstructured interviews (van der Zee, Bakker, \& Bakker, 2002), organizational norms (Chen, Tsai, \& Hu, 2008), perceived lack of diffusion in the field (König, Kle- he, Berchtold, \& Kleinmann, 2010), or the lack of coverage in the practitioner-oriented literature (Roulin \& Bangerter, 2012). Yet, a large majority of this research is limited in that it has examined structured interviews at a general level, only focused on a few specific components (e.g., question types), or investigated a limited number of antecedents.

The present study contributes to the personnel selection and employment interview literatures in two critical ways. First, we empirically examine professional interviewers' use of seven central components of structured interviews: rapport building, question sophistication, question consistency, probing, note taking, use of a panel of interviewers, and standardized evaluation. By doing so, we expand on

\footnotetext{
Corresponding author:

Nicolas Roulin

Email: nicolas.roulin@smu.ca
}

The authors thank the University of Manitoba Asper Career and Development Center for their help with the data collection, as well as Ryan Cook and Stephanie Law for their help with data preparation. This project was supported by an Insight Grant from the Social Science and Humanities Research Council of Canada (SSHRC Grant \# 435-2015-0566) and a SSHRC scholarship to the third author. 
the findings of Chapman and Zweig (2005) and respond to the recent call for further research examining structure components separately (Levashina et al., 2014). Second, we examine three types of antecedents of structured interview components use: interviewers' personal and professional background (e.g., experience, training), interview focus (selection vs. recruitment), and personality traits (e.g., agreeableness, extraversion). As such, we go beyond previous findings, which have relied on intentions to structure rather than actual usage or focused on the use of structured interviews in general rather than the roles of specific components (e.g., Lievens \& De Paepe, 2004; Tsai, Chen, Chen, \& Tseng, 2016; van der Zee et al., 2002). In short, the present study investigates a number of important antecedents of interview structure use, using real interviews and a broad array of interview structure components.

\section{Structured Interview Dimensions}

There is ample evidence that interviews are more reliable, valid, and fair when interviewers prepare questions ahead of time and base them on a job analysis, ask more sophisticated questions (e.g., past oriented or situational), ask the same questions to all applicants, in the same order, and without prompts, use a panel of interviewers, and rate each response using anchored rating scales (e.g., Campion, Campion, \& Hudson, 1994; Huffcutt \& Arthur, 1994; McCarthy, Van Iddekinge, \& Campion, 2010). Campion et al. (1997) described the structured interview as composing up to 15 dimensions with different levels of structure for each dimension. Yet, many studies have either conceptualized structure as unidimensional (or on a continuum with the option of using a semistructured format; e.g., Dipboye, Gaugler, Hayes, \& Parker, 2001; Kohn \& Dipboye, 1998; Motowidlo et al., 1992) or have focused on one specific component (such as question type; e.g., Latham \& SueChan, 1999).

More recent work has described structured interview components as loading onto four factors: rapport building, question sophistication, question consistency, and evaluation standardization (Chapman \& Zweig, 2005). Intercorrelations between factors were also fairly low (ranging from -.24 to .51 ), thus confirming that interview structure is best understood as both multidimensional and continuous. Yet, despite the considerable value of Chapman and Zweig's measure, there are some limitations to this measure and framework, including some psychometric properties that do not consistently meet agreed-upon thresholds, with low factor loadings for some items and low reliabilities for some factors (e.g., question sophistication). In addition, although originally they included items for some important additional structure elements such as probing, note taking, or the use of panels, these did not load onto the primary dimensions and hence did not receive further investigation or integration into their framework. Thus, the dimensionality of structured interviewing behaviors seems more complex than popular aggregate models suggest, and investigating specific components may lead to distinct relationships and implications.

\section{Factors Influencing the Use of Structured Interviews and Structure Components}

The structured interview remains a vexing paradox for personnel selection researchers. It demonstrates excellent psychometric properties - for instance, much higher criterion-related validity as compared to unstructured interviews (Huffcutt \& Arthur, 1994). Yet, it is underused in practice, making it a prime example of the academic-practitioner gap (e.g., Roulin \& Bangerter, 2012; Ryan et al., 1999). As an example, Lievens and De Paepe (2004) found only $20 \%$ of interviewers were using high levels of question consistency and $4 \%$ using high levels of evaluation standardization. Several researchers have attempted to understand the reason for this lack of diffusion. For instance, interviewers tend to have more positive attitudes toward unstructured than structured interviews (van der Zee et al., 2002) and underestimate the usefulness, legality, or diffusion of structured interviews (König et al., 2010; Rynes, Bartunek, \& Daft, 2001; Terpstra \& Rozell, 1997). Such perceptions can be partly due to the limited diffusion of the benefits of structure in popular media (e.g., practitioner-oriented books; Roulin \& Bangerter, 2012). Limited use is also associated with characteristics of the interviewer or their organization (Chen et al., 2008; Lievens \& De Paepe, 2004; van der Zee et al., 2002). Although we have some general knowledge of why interviewers choose to adopt or avoid structured interviewing behaviors, there is a scarcity of research examining specific antecedents of structure components (see Chapman $\&$ Zweig, 2005 for a rare exception). We argue that there are likely differential antecedents to different structure components. However, given the limited theoretical background and empirical research available, we take an exploratory approach and examine three categories of potential antecedents: (a) personal and professional background, (b) interview focus, and (c) personality. Our goal is to provide initial evidence to further our understanding of differential antecedents of structure use, help close the academic-practitioner gap, and motivate more research in this area.

\section{Personal and Professional Background}

Graves (1993) proposed that interviewers' individual characteristics, such as experience, influence the way they process information and ultimately their preferences for conducting interviews. However, empirical evidence is somewhat mixed regarding the association between interviewing experience and use of (or reactions towards) structure, with studies reporting no (Lievens \& De Paepe, 
2004) or negative (Chen et al., 2008) relationships. More experienced interviewers value discretion and control over the way the interview is conducted (Lievens \& De Paepe, 2004; van der Zee et al., 2002), which should make them more likely to engage in rapport building and probing but less likely to ask questions in a consistent manner and to standardize their evaluation.

Training may also play a key role in how the interview is conducted. For instance, training can help educate interviewers about specific structure components (e.g., questioning techniques; Anderson, 1992) and might increase adoption of structured techniques (e.g., Levashina et al., 2014). Consistent with this, trained interviewers report slightly more positive reactions to structured interviews (Chen et al., 2008) and are more likely to use more structured interviews (Lievens \& De Paepe, 2004). But the effect of training may be constrained to certain components. Indeed, Chapman and Zweig (2005) found training to be positively associated with the use of question sophistication and evaluation standardization but not rapport building or question consistency. Similarly, trained interviewers may better understand the value of taking notes to keep records and more objectively compare applicants.

Institutional factors, such as organization size, may also play a role in the adoption of valid selection methods (Klehe, 2004). For instance, larger organizations have more resources and can more easily afford to use multiple interviewers (i.e., panels). Because they have stricter reporting standards and are subject to more scrutiny, larger organizations might require interviewers to keep records of their interviews and thus encourage note taking. In summary, we propose to explore the following research question about interviewers' background and use of structure components:

Research Question 1. What are the relationships between interviewing experience, interview training, and organization size and the use of specific structure components?

\section{Interview Focus}

When conducting interviews, interviewers can have multiple objectives (Dipboye, 1994; Dipboye, Macan, \& Shahani-Denning, 2012). Two central goals involve recruitment (i.e., making the job or organization attractive to applicants) and selection (i.e., assessing applicants' qualifications to identify the best ones). Chapman and Zweig (2005) found that interviewers more focused on selection (vs. recruitment) relied on more standardized evaluation and in some cases question consistency, but focus was unrelated to the other components. However, other structured components could also be relevant. For instance, asking more sophisticated questions in a consistent way helps increase predictive validity, which is central to effective selection (Campion et al., 1994; Latham \& Sue-Chan, 1999) but might also trigger more negative applicant reactions, which is central to successful recruitment (Dipboye, 1994; Kohn \& Dipboye, 1998). In contrast, rapport building could help with recruitment goals. As such, we explore the relationships between the focus of the interview and structure components use with our second research question:

Research Question 2. Do interviewers who are more selection focused use structure components differently than those who are more recruitment focused?

\section{Personality}

In addition to demographics or experience, Graves (1993) argued that interviewers' personality influence the way they conduct interviews. For instance, their level of extraversion should influence their communication style and thus the amount and type of information they elicit from applicants. Tsai et al. (2016) recently empirically examined the role of interviewer personality and showed that agreeableness, conscientiousness, and (to a lesser extent) extraversion were positively associated with intentions to use structured interviews. However, their study was limited to intentions and not actual behaviors (which might only be weakly related, van der Zee et al., 2002), and they looked at overall structure (summing across structure components). We argue that personality could be particularly relevant for specific structure components. For instance, extraverts are more talkative and sociable (Lee \& Ashton, 2004), and could thus be more likely to engage in rapport building to start the interview with an informal conversation with applicants. They could also be likely to use more probing, because it allows them to speak more and have a two-way conversation with applicants. However, extraversion is arguably less relevant for other components (e.g., question consistency). In addition, individuals low in agreeableness tend to be more impatient, more critical, and less trusting (Lee \& Ashton, 2004). Low-agreeableness interviewers might thus be more likely to use probing, to quickly obtain more information from applicants or voice their reservations about applicants' initial responses. Conscientious individuals are more organized, self-disciplined, and detail oriented (Lee \& Ashton, 2004). This could make them particularly prone to take notes during the interview so that they can keep track of the information gathered from the applicant. Conscientious interviewers could also value a more objective, consistent, and standardized approach to ask questions and rate applicants' responses. We thus examine the relationships between interviewer personality and interview structure component use:

Research Question 3. What are the relationships between personality traits (e.g., extraversion, agreeableness, conscientiousness) and the use of structure components? 


\section{METHOD}

\section{Sample and Procedure}

Our sample comprised 131 experienced interviewers who conducted a total of 817 campus interviews to hire senior business students from a Canadian university. Interviewers were from local organizations active in a variety of industries (e.g., retail, banking, insurance, agriculture, government). A majority (61\%) of interviewers were female, mean age was $35.08(S D=8.67)$, they had an average 7.53 $(S D=10.02)$ years of interviewing experience, and $67 \%$ were in a managerial role. Fifty-five percent of interviewers received formal interview training (19.22 hours on average, $S D=22.08$ ). All interviews were high stakes, with multiple applicants competing for paid internship positions (4-month job placements as part of a cooperative education program). Interviewers spent half a day to a full day on campus conducting interviews (with up to 10 candidates for one or two positions). We used this opportunity to provide them with a questionnaire package including all measures (they also rated the performance of each candidate they interviewed, but these data are not used in the present study). They received the package from the university career center upon arrival, were advised to complete it before their first interview (but in practice could complete it anytime during that day), and had to bring back their completed package at the end of the day. They were compensated with a $\$ 15$ gift card. In cases when multiple interviewers were involved $(59 \%$ of the time), only one of the interviewers completed the measures.

\section{Measures}

Structured interview components. We used a revised version of the scale by Chapman and Zweig (2005) with a 5 -item measure of rapport building ( $\alpha=.73$, e.g., "I begin the interview with light conversation"), a 4-item measure of question sophistication ( $\alpha=.59$, e.g., "I ask questions about how the candidate would go about performing a task"), a 5 -item measure of question consistency ( $\alpha=.83$, e.g., "My questions are consistent across candidates"), and a 5-item measure of evaluation standardization $(\alpha=.88$, e.g., "I use a formal rating system that I apply to each candidate"). We created a 2 -item measure of probing $(\alpha=.57$, e.g., "If a candidate doesn't answer a question fully, I will ask them for more information") and a 1-item measure of note taking ("I take detailed notes during the interview to help me make my evaluation") derived from Campion et al. (1997). All items are included in Appendix A, and all responses were provided on a $1-5$ Likert scale $(1=$ never; $5=$ always). In addition, the use of panel interview was measured with one item: "Today, interviews are conducted by..." one interviewer (coded 0) versus two or more interviewers (coded 1). Overall, our study includes seven structure components (versus 4 in Chapman \& Zweig, 2005) and a longer and more reliable measure of rapport building. Reliabilities for the other measures were similar to Chapman and Zweig (2005), including the lower reliability for question sophistication. In addition, to facilitate comparisons with previous research, we also computed an overall interview structure score as the mean across the seven components (after reversing the scores for rapport building and probing, and multiplying the panel $1 / 0$ score by 5$){ }^{1}$

Interviewer background. Interviewers reported their age, gender, job tenure, organization size (on a scale from 1 $=1-50$ employees to $8=$ over 10,000 employees $)$; whether they received formal training in how to conduct interviews (yes/no); and interviewing experience (years/months and the number of interviews conducted).

Interview focus. Similarly to Chapman and Zweig (2005), we used one item: "Typically when I conduct an interview for my organization, I would say the focus is..." with $1=$ recruiting/attraction and $5=$ screening/selection.

Interviewer personality. We used the 24-item Brief HEXACO Inventory (De Vries, 2013), with 4-item measures for honesty-humility, emotionality, extraversion, agreeableness, conscientiousness, and openness. Reliabilities were low but similar to those reported in the original scale validation study, and we expected this given that this short measure aims at ensuring a broad coverage of the various facets for each trait (De Vries, 2013). ${ }^{2}$

1 We revised the Chapman and Zweig (2005) scale to a modest extent for several reasons. First, in their original paper, the three-item rapportbuilding scale had an alpha of .50. As such, we created two additional rapport-building items, which did result in an increased reliability. In addition, for the question consistency measure, expert review indicated two of the items were not clearly related to question consistency and so were removed (e.g., "questions are linked to a job description"). These same two items had very low factor loadings in the original paper by Chapman and Zweig. Finally, for evaluation standardization, one item ("I make my decisions based on gut feelings about the candidate) notably dropped the reliability of the scale in previous studies we had conducted, and had the lowest factor loading in Chapman and Zweig's study, so was dropped here. 2 Internal consistency reliabilities ranged from .23 to .62. However, the scales mix diverse items to maximize content coverage. For these types of measures, low internal consistency should thus not be taken as an indicator of the measures being error laden. Several authors (e.g., De Vries, 2013; McCrae, Kurtz, Yamagata, \& Terracciano, 2011) argue that temporal stability is the appropriate reliability measure for short measures of already-established personality traits. The HEXACO-24 has demonstrated strong temporal stability reliability (with two months stability ranging from .71 for Extraversion to .79 for Conscientiousness), high self-other agreement (ranging from .39 for Agreeableness to .58 for Emotionality), and convergent validity (correlations with the full HEXACO-PI-R ranging from .59 to .83 ) indicating the scale is indeed reliable and valid (De Vries, 2013). 


\section{RESULTS}

Descriptive statistics and correlations among all variables are presented in Table 1. Because question type has been largely examined in the literature, we also report correlations specifically for the use of situational and past-behavioral questions. ${ }^{3}$ Interviewers reported higher levels of use of some structure components (e.g., $M=3.99$ for question consistency, $M=3.85$ for note taking), but evaluation standardization was less widely adopted $(M=2.66)$. Interviewers also relied extensively on less-structured techniques like rapport building $(M=3.89)$ or probing ( $M$ $=4.03$ ). Moreover, we observed small to moderate correlations among the structure components $(r$ ranging from -.23 to .64), suggesting that interviewers tend to use some components but not others.

We examine our research questions with zero-order correlation coefficients (Table 1). Looking at interviewers' personal and professional background, we found that interviewing experience was positively related to probing $(r=$ $.18)$ and note taking $(r=.27)$ when looking at the number of interviews conducted but not when looking at years of experience. In contrast, years of experience were more strongly - but negatively - associated with question sophistication $(r=-.30)$. When looking specifically at question type, we found that years of experience were negatively associated with the use of both situational questions $(r=-.25)$, and behavioral questions $(r=-.27)$, whereas the numbers of interviews conducted was only negatively related to using situational questions $(r=-.24)$. However, experience was not associated with rapport building, question consistency, the use of panels, or evaluation standardization. Training was positively related to question consistency $(r=.33)$, note taking $(r=.28)$, and evaluation standardization $(r=$ .39) but not with other components. Organization size was only positively associated with probing $(r=.26)$ and using panels $(r=.20)$.

Interviewers who focused more on selection (vs. recruitment) used more question sophistication $(r=.26)$, question consistency $(r=.19)$, note taking $(r=.20)$, and evaluation standardization $(r=.27)$. They also used slightly less rapport building, although the correlation was not significant.

Regarding interviewers' personality, extraversion was positively associated with rapport building $(r=.31)$ and probing $(r=.24)$. Conscientiousness was positively correlated with evaluation standardization $(r=.22)$ but was unrelated to note taking or question consistency. Emotionality was negatively related to rapport-building $(r=-.20)$, whereas openness was positively associated with rapport building $(r=.26)$ and note taking $(r=.27)$. Honesty-humility and agreeableness were unrelated to any structure component. ${ }^{4}$

To get a better understanding of the importance of each antecedent, we also report the results of regression analyses conducted with our key antecedents (i.e., interviewer background, interview focus, and personality) predicting each of the seven structure components in Table 2. Overall, the key significant relationships observed in the correlations were largely replicated in the regressions, with two main exceptions (nonsignificant effects for extraversion-probing and conscientiousness-evaluation standardization). Taken together, our antecedents explained between 9\% (panel) and $28 \%$ (evaluation standardization) of structure component use. Table 2 also includes the rescaled relative weights (i.e., the relative percentage of total variance in component use explained by each antecedent; Tonidandel \& LeBreton, 2015). This highlights the importance of each type of antecedent for the various structure component use. Interviewers' background appears to play a major role in asking consistent questions ( $62.8 \%$ of the explained variance), probing $(50.7 \%)$, using panels $(68.4 \%)$, or standardizing evaluation $(59 \%)$. The focus of the interview matters most for question sophistication (45.1\%). Interviewers' personality seems to be the main driver for engaging in rapport building $(82.3 \%)$.

When examining the overall structure score, only three of our antecedents were significantly correlated with structure use: interview training $(r=.21)$, having a focus on selection $(r=.24)$, and emotionality $(r=.20)$. Together, our antecedents explained $15 \%$ of variance in overall interview structure use in the regression analysis. Also, the rescaled relative weights confirmed that a focus on selection (30.5\%) and training $(22.6 \%)$ were the main contributors of the overall use of structure.

\section{DISCUSSION}

\section{Theoretical and Practical Contributions}

Our results give insight into how and when different components of interview structure are used, utilizing a multifaceted and continuous approach to structure, and a sample of professional interviewers reporting their use of these components. First, our findings highlight that the academicpractitioner gap surrounding structured interviews is likely confined to specific components. Interviewers reported asking quite sophisticated questions, asking questions consistently, and taking notes, and a majority of interviews are conducted by multiple interviewers. Yet, many interviewers were hesitant to use a more standardized evaluation and seemed attached to rapport building and probing, consistent with past studies (e.g., Chapman \& Zweig, 2005; Lievens \& De Paepe, 2004).

Our study also provides a more comprehensive under-

3 These are items from the question sophistication scale.

4 Following the recommendation of a reviewer, we also report the detailed correlations between facet-level personality and the use of the seven structure components in Appendix B. Results generally replicated those at the trait level. 
Table 1.

Means, Standard Deviations, and Correlations Among Study Variables

\begin{tabular}{|c|c|c|c|c|c|c|c|c|c|c|c|c|c|c|c|}
\hline & & M & SD & 1 & 2 & 3 & 4 & 5 & 6 & 7 & 8 & 9 & 10 & 11 & 12 \\
\hline 1 & Rapport building & 3.89 & 0.67 & & & & & & & & & & & & \\
\hline 2 & Question sophistication & 3.59 & 0.63 & -.04 & & & & & & & & & & & \\
\hline 3 & Situational questions & 3.87 & 1.01 & .06 & $.79^{* *}$ & & & & & & & & & & \\
\hline 4 & Behavioral questions & 4.21 & 0.89 & -.12 & $.67^{* *}$ & $.44 * *$ & & & & & & & & & \\
\hline 5 & Question consistency & 3.99 & 0.80 & $-.23 * *$ & .17 & .15 & $.34 * *$ & & & & & & & & \\
\hline 6 & Probing & 4.03 & 0.65 & $.28 * *$ & $.22 *$ & .13 & $.20^{*}$ & -.13 & & & & & & & \\
\hline 7 & Note taking & 3.85 & 1.18 & -.13 & $.30^{* *}$ & .16 & $.35^{* *}$ & $.64 * *$ & .11 & & & & & & \\
\hline 8 & Panel interview & 0.59 & 0.49 & -.12 & .14 & .05 & $.21 *$ & .00 & .12 & .06 & & & & & \\
\hline 9 & Evaluation standardization & 2.66 & 1.07 & -.10 & .16 & .10 & $.23 * *$ & $.44 * *$ & -.13 & $.34 * *$ & -.11 & & & & \\
\hline 10 & Overall structure & 3.02 & 0.56 & $-.42 * *$ & $.38 * *$ & $.24 * *$ & $.47 * *$ & $.61 * *$ & -.13 & $.62 * *$ & $.54 * *$ & $.47 * *$ & & & \\
\hline 11 & Selection- vs. recruitment-focus & 3.52 & 1.20 & -.15 & $.26^{* *}$ & $.21 *$ & $.28^{* *}$ & $.19^{*}$ & -.05 & $.20 *$ & -.03 & $.27 * *$ & $.24 * *$ & & \\
\hline 12 & Gender (male) & 0.42 & 0.63 & .12 & -.11 & -.12 & $-.21 *$ & -.12 & -.10 & -.10 & -.09 & -.08 & -.16 & -.17 & \\
\hline 13 & Age & 35.08 & 8.66 & -.02 & -.09 & -.08 & -.08 & .10 & -.10 & .07 & -.10 & .13 & .02 & .04 & .11 \\
\hline 14 & Job tenure & 3.66 & 4.29 & .02 & $-.27 * *$ & -.13 & $-.22 *$ & .01 & -.05 & -.10 & -.12 & -.08 & -.16 & -.15 & .17 \\
\hline 15 & Organization size & 4.71 & 2.40 & -.15 & .10 & .04 & $.18^{*}$ & -.16 & $.26^{* *}$ & -.13 & $.20^{*}$ & -.07 & .04 & .04 & -.04 \\
\hline 16 & Formal interview training & 0.55 & 0.50 & .02 & .13 & -.01 & .14 & $.33 * *$ & .10 & $.28 * *$ & -.08 & $.39^{* *}$ & $.21 *$ & .01 & .08 \\
\hline 17 & Interviewing experience (years) & 7.53 & 10.02 & .12 & $-.30 * *$ & $-.25 * *$ & $-.27 * *$ & -.03 & -.10 & -.06 & -.12 & -.06 & -.17 & -.15 & $.56^{* *}$ \\
\hline 18 & Number of interviews conducted & 172.60 & 284.83 & -.02 & -.10 & $-.24 * *$ & .11 & .16 & $.18^{*}$ & $.27 * *$ & .07 & -.04 & .11 & .01 & -.16 \\
\hline 19 & Interviewer honesty-humility & 4.08 & 0.52 & .07 & .08 & .02 & .09 & .01 & .10 & .04 & -.03 & .01 & -.02 & -.10 & $-.27 * *$ \\
\hline 20 & Interviewer emotionality & 2.69 & 0.59 & $-.20^{*}$ & -.07 & -.12 & .00 & .11 & -.15 & .15 & .11 & .05 & $.20 *$ & -.02 & $-.22 *$ \\
\hline 21 & Interviewer extraversion & 4.18 & 0.50 & $.31 * *$ & -.07 & -.06 & -.06 & -.08 & $.24 * *$ & .06 & -.10 & -.02 & -.17 & .02 & .00 \\
\hline 22 & Interviewer agreeableness & 3.19 & 0.46 & .09 & .03 & -.02 & .01 & .10 & -.05 & .02 & .01 & .07 & .05 & -.10 & .03 \\
\hline 23 & Interviewer conscientiousness & 3.77 & 0.47 & .17 & .09 & .04 & .17 & -.01 & .13 & -.06 & .08 & $.22 *$ & .05 & .07 & -.01 \\
\hline 24 & Interviewer openness & 3.45 & 0.56 & $.26^{* *}$ & .09 & .07 & .01 & .07 & .12 & $.27 * *$ & -.01 & .16 & .09 & .01 & .05 \\
\hline
\end{tabular}

standing of antecedents to interview structure, expanding on past research that has been limited to examining the structured interview in general (van der Zee et al., 2002), intentions or reactions only (Chen et al., 2008; Tsai et al., 2016), or a limited number of antecedents and structure components (Chapman \& Zweig, 2005). Our findings suggest that interviewers' background, personality, and interview focus explained between 9 and $28 \%$ of component usage (and $15 \%$ of overall structure use). Our findings also suggest that interviewers' background and the focus of the interview play a role for positive components (or best practices) of structured interviews (e.g., Campion et al., 1997; Levashina et al., 2014). For instance, interview training played a more major role for the use of question consistency, note taking, and evaluation standardization (and overall structure use). This illustrates the importance of properly training interviewers about evidence-based best practices. It may also highlight that interview training initiatives could be shifted to focus on emphasizing some of these other components. For instance, organizations might be encouraged to focus their training on less-popular components, such as evaluation standardization, and emphasize the practical advantage of such techniques (e.g., increasing reliability and reducing biases). Our findings show that training can be relevant also for experienced interviewers, given that years of experience was negatively associated with the use of sophisticated questions. Interestingly, years of experience and number of interviews conducted were differently related to the use of structure components. This highlights the importance of distinguishing various forms of experience (i.e., conducting a few interviews a year for many years vs. regular interviewing duties).

An interview focused on selecting the best applicant (vs. recruiting) was particularly important for determining how an interview is conducted, with selection goals being associated with more sophisticated questions (but also more 
Table 1 (continued).

\begin{tabular}{|c|c|c|c|c|c|c|c|c|c|c|c|c|}
\hline & & 13 & 14 & 15 & 16 & 17 & 18 & 19 & 20 & 21 & 22 & 23 \\
\hline 14 & Job tenure & $.45^{* *}$ & & & & & & & & & & \\
\hline 15 & Organization size & $-.30 * *$ & $-.19 *$ & & & & & & & & & \\
\hline 16 & Formal Interview training & .14 & .02 & .10 & & & & & & & & \\
\hline 17 & Interviewing experience (years) & $.38^{* *}$ & $.38^{* *}$ & $-.26^{* *}$ & $.31 * *$ & & & & & & & \\
\hline 18 & Number of interviews conducted & .02 & .06 & .00 & $.26 * *$ & .05 & & & & & & \\
\hline 19 & Interviewer honesty-humility & .08 & -.02 & -.06 & .03 & $-.20^{*}$ & .03 & & & & & \\
\hline 20 & Interviewer emotionality & -.04 & -.14 & .02 & .02 & -.02 & .03 & .11 & & & & \\
\hline 21 & Interviewer extraversion & .07 & .04 & -.05 & .03 & .06 & .10 & .06 & $-.33^{* *}$ & & & \\
\hline 22 & Interviewer agreeableness & .00 & .06 & .12 & .08 & .08 & -.03 & $.24 * *$ & -.03 & .08 & & \\
\hline 23 & Interviewer conscientiousness & $-.21^{*}$ & -.04 & .09 & .14 & -.10 & -.13 & $.24 * *$ & -.03 & .08 & .17 & \\
\hline 24 & Interviewer openness & $.21^{*}$ & .04 & $-.22 *$ & .07 & .01 & .05 & .07 & -.07 & $.29 * *$ & .12 & .03 \\
\hline
\end{tabular}

Note. $N=131$ professional interviewers. ${ }^{*} p<.05,{ }^{*} p<.01$.

consistent questions, a more standardized rating process, and structure overall). Together with the research suggesting that less structured components can help ensure more positive applicant reactions when recruitment is a priority for the organization (Conway \& Peneno, 1999), these findings highlight that interview goals are important considerations for deciding how to conduct an interview.

In terms of personality, limited work has examined interviewer personality in relation to structure use. As an exception, Tsai et al. (2016) found that some personality traits were associated with positive intentions to use structured interviews in general in an Asian sample. Our findings, in a Western sample, suggest that interviewer personality was mostly associated with components often discouraged by structured interview proponents (e.g., Campion et al., 1997). For instance, more extraverted interviewers reported using more rapport building and probing, possibly to appease their need to talk and appear sociable (Lee \& Ashton, 2004). This suggests that it might be difficult to completely eliminate less-structured components without encountering resistance from some interviewers. We note that rapport building and probing are treated as indicative of lower structure here, which is consistent with the majority of the formative literature. For instance, past research highlighted concerns that rapport building can contain non-job-related information and create biased early impressions (Dipboye, 1994; Levashina et al., 2014) and should thus be limited (Campion et al., 1994; Campion et al., 1997; Campion et al., 1988; Levashina et al., 2014). However, we recognize that rapport building may play a central role for accomplishing important goals in an interview, such as helping recruitment outcomes. It may also be less problematic if limited or separated from the main portion of the interview or structured to limit non-job-related information. As such, organizations might be advised to allow for rapport building or probing but to provide guidance to their interviewers. For instance, instead of preventing interviewers from probing, organizations could instruct them to ask a small number of pre-established follow-up questions to obtain more precise information (e.g., about the situation the applicant faced or their behaviors). However, more research is needed on ways to improve and incorporate rapport building in a responsible way where desired.

Overall, relationships between structure components and other personality traits were quite small. For instance, we found a small correlation between conscientiousness and evaluation standardization but no relationship with note taking or question consistency. Personality seems to play a 
Table 2.

Regressions Predicting Structure Components Use and Relative Weight Analysis

\begin{tabular}{|c|c|c|c|c|c|c|c|c|c|c|c|c|c|c|c|c|}
\hline & \multicolumn{2}{|c|}{$\begin{array}{l}\text { Rapport } \\
\text { Building }\end{array}$} & \multicolumn{2}{|c|}{$\begin{array}{c}\text { Question } \\
\text { Sophistication }\end{array}$} & \multicolumn{2}{|c|}{$\begin{array}{c}\text { Question } \\
\text { Consistency }\end{array}$} & \multicolumn{2}{|c|}{ Probing } & \multicolumn{2}{|c|}{ Note Taking } & \multicolumn{2}{|c|}{$\begin{array}{c}\text { Panel } \\
\text { Interview }\end{array}$} & \multicolumn{2}{|c|}{$\begin{array}{c}\text { Evaluation } \\
\text { Standardization }\end{array}$} & \multicolumn{2}{|c|}{$\begin{array}{c}\text { Overall } \\
\text { Structure }\end{array}$} \\
\hline & betas & RW & betas & RW & betas & RW & betas & RW & betas & RW & betas & RW & betas & RW & betas & RW \\
\hline Experience & -.01 & 0.4 & -.14 & 16.3 & .07 & 6.4 & $.18^{*}$ & 14.6 & $18^{*}$ & 17.6 & .12 & 9.7 & -.14 & 4.2 & .06 & 4.7 \\
\hline Training & -.03 & 0.4 & .13 & 13.0 & $.33^{* *}$ & 41.8 & -.04 & 0.5 & $.22 *$ & 20.9 & -.12 & 6.7 & $.39 * *$ & 51.0 & $.20 *$ & 30.5 \\
\hline Organization size & -.10 & 7.4 & .08 & 6.67 & $-.22 *$ & 14.6 & $.32 * *$ & 35.6 & -.14 & 8.2 & $.22 *$ & 52.0 & -.13 & 3.8 & -.00 & 0.5 \\
\hline Selection focus & -.15 & 9.4 & $.22 *$ & 45.1 & $.21^{*}$ & 16.7 & -.09 & 3.4 & $.22 *$ & 15.1 & -.09 & 7.1 & $.22 * *$ & 17.6 & $.19^{*}$ & 22.6 \\
\hline Honesty-humility & -.04 & 0.5 & .00 & 0.5 & .01 & 0.3 & .12 & 4.8 & .05 & 1.0 & -.07 & 3.5 & .00 & 0.3 & -.04 & 0.9 \\
\hline Emotionality & -.06 & 7.4 & -.06 & 1.8 & .03 & 0.8 & -.12 & 7.2 & .14 & 6.7 & .06 & 5.8 & .00 & 0.1 & .11 & 11.4 \\
\hline Extraversion & $.22 * *$ & 32.3 & -.12 & 8.9 & -.07 & 1.5 & .11 & 11.4 & .03 & 4.5 & -.07 & 5.3 & -.09 & 1.6 & -.15 & 14.8 \\
\hline Agreeableness & -.04 & 0.5 & -.02 & 0.4 & $.21^{*}$ & 13.2 & -.17 & 6.7 & .08 & 4.7 & .01 & 1.1 & .10 & 4.5 & .13 & 10.0 \\
\hline Conscientiousness & $.21 * *$ & 20.6 & .05 & 5.7 & -.13 & 3.7 & .12 & 8.0 & -.13 & 4.5 & .11 & 7.8 & .11 & 8.6 & -.02 & 0.4 \\
\hline Openness & .16 & 21.0 & .06 & 1.5 & .01 & 1.1 & .15 & 7.8 & $.23 * *$ & 22.7 & .05 & 1.0 & .14 & 8.4 & .10 & 4.3 \\
\hline F-value & $2.53 * *$ & & 1.42 & & $3.54 * *$ & & $2.79 * *$ & & $4.20 * *$ & & 1.08 & & $4.26^{* *}$ & & $1.97^{*}$ & \\
\hline $\mathrm{R}^{2}$ & .19 & & .11 & & .24 & & .20 & & .28 & & .09 & & .28 & & .15 & \\
\hline
\end{tabular}

Note. $N=131$ professional interviewers. Experience is in 100s of interviews conducted. Values in the left columns are standardized betas. Values in the right columns are Rescaled Relative Weights in percent of total variance explained (Tonidandel \& LeBreton, 2015).

$* p<.05, * * p<.01$.

relatively minor role on the whole, which is consistent with Tsai et al. (2016), who found personality to account for $13 \%$ of intentions to use structured interviews. Interestingly, age, gender, tenure, or experience were seldom associated with component adoption, except, to some extent, a tendency for more experienced interviewers to use less sophisticated questions, probe more, and take more notes.

\section{Limitations and Future Research Directions}

Despite the contributions highlighted above, this study has a number of limitations and calls for further research. First, the reliability of some structure components (particularly question sophistication) was somewhat low. Although our revised measures were somewhat more reliable than those in Chapman and Zweig (2005), this suggests that question sophistication may be better measured using more general items or that particular types of questions (e.g. behavioral/situational) should be assessed and reported separately. In addition, we encourage researchers to replicate our findings using longer (and more reliable) personality measures. Second, our data are cross-sectional and based on self-reports. This was necessary given the nature of the constructs measured (e.g., personality, interview practices) and derived from the opportunity to access a large number of professional interviewers at one point in time. Replications could use time-separated or more objective measures, although too much time separation may be problematic for examining interviewer factors at the time they conduct the interview. Third, although $59 \%$ of the interviews were conducted by two or more interviewers, we only obtained responses from one interviewer. Interviewers likely had different personality profiles and perhaps differed in terms of 
their focus, which could have impacted the use of structure components. Future research could examine the combined effect of both interviewers' personality on structure component use. Fourth, our list of antecedents is certainly not exhaustive. Future research could, for instance, examine interviewers' education background (e.g., I-O psychology vs. HR) or their level of familiarity with selection research. Research could also explore interviewers' attitudes toward specific structure components and whether such attitudes are associated with their use. Similarly, we only asked interviewers whether they received formal interview training or not, but did not examine the content of their training. The associations we demonstrated between training and specific structure elements gives some overall idea of the types of aspects that are contained in training. But it is possible that some interviewers were trained only on specific components and that they only use the component on which they were trained. Future research could examine how interviewers are trained, on what components they are trained (for a rare exception, see Chapman \& Zweig, 2005), and whether specific training is associated with specific component use in practice. Finally, our findings are based on interviews with young and inexperienced, but highly educated, applicants for a paid internship position. Studies could examine if structure components are used differently when interviewing other populations (e.g., more experienced or less educated) or for other types of jobs (e.g., full-time positions).

\section{REFERENCES}

Anderson, N. (1992). Eight decades of employment interview research: A retrospective meta-review and prospective commentary. European Work and Organizational Psychologist, 2, 1-32. doi:10.1080/09602009208408532

Campion, M. A., Campion, J. E., \& Hudson, P. J. J. (1994). Structured interviewing: A note on incremental validity and alternative question types. Journal of Applied Psychology, 79, 998-1002. doi:10.1037/0021-9010.79.6.998

Campion, M. A., Palmer, D. K., \& Campion, J. E. (1997). A review of structure in the selection interview. Personnel Psychology, 50, 655-702. doi:10.1111/j.1744-6570.1997.tb00709.x

Campion, M. A., Pursell, E. D., \& Brown, B. K. (1988). Structured interviewing: Raising the psychometric properties of the employment interview. Personnel Psychology, 41, 25-42. doi:10.1111/j.1744-6570.1988.tb00630.x

Chapman, D. S., \& Zweig, D. I. (2005). Developing a nomological network for interview structure: Antecedents and consequences of the structured selection interview. Personnel Psychology, 58, 673-702. doi:10.1111/j.17446570.2005.00516.x
Chen, Y. C., Tsai, W. C., \& Hu, C. Y. (2008). The influences of interviewer-related and situational factors on interviewer reactions to high structured job interviews. International Journal of Human Resource Management, 19, 1056-1071. doi:10.1080/09585190802051345

Conway, J. M., \& Peneno, G. M. (1999). Comparing structured interview question types: Construct validity and applicant reaction. Journal of Business and Psychology, 13, 485-506. doi:10.1023/A:1022914803347

De Vries, R. E. (2013). The 24-item brief HEXACO inventory (BHI). Journal of Research in Personality, 47, 871-880. doi:10.1016/ j.jrp.2013.09.003

Dipboye, R. L. (1994). Structured and unstructured selection interviews: Beyond the job-fit model. In G. R. Ferris (Ed.), Research in personnel and human resources management (Vol. 12, pp. 79-123). Greenwich, CT.: JAI Press.

Dipboye, R. L., Gaugler, B. B., Hayes, T. L., \& Parker, D. (2001). The validity of unstructured panel interviews: More than meets the eye? Journal of Business and Psychology, 16, 35-49. doi:10.1023/A:1007883620663

Dipboye, R. L., Macan, T., \& Shahani-Denning, C. (2012). The selection interview from the interviewer and applicants perspective: Can't have one without the other. In N. Schmitt (Ed.), The Oxford handbook of personnel selection and assessment (pp. 323-352). New York, NY: Oxford University Press.

Graves, L. M. (1993). Sources of individual differences in interviewer effectiveness: A model and implications for future research. Journal of Organizational Behavior, 14, 349-370. doi:10.1002/job.4030140406

Huffcutt, A. I., \& Arthur, W. J. (1994). Hunter and Hunter (1984) revisited: Interview validity for entry-level jobs. Journal of Applied Psychology, 79, 184-190. doi:10.1037/00219010.79.2.184

Klehe, U.-C. (2004). Choosing how to choose: Institutional pressures affecting the adoption of personnel selection procedures. International Journal of Selection and Assessment, 12, 327-342. doi:10.1111/j.0965-075X.2004.00288.x

Kohn, L. S., \& Dipboye, R. L. (1998). The effects of interview structure on recruiting outcomes. Journal of Applied Social Psychology, 28, 821-843. doi:10.1111/j.1559-1816.1998. tb01733.x

König, C. J., Klehe, U.-C., Berchtold, M., \& Kleinmann, M. (2010). Reasons for being selective when choosing personnel selection procedures. International Journal of Selection and Assessment, 18, 17-27. doi:10.1111/j.1468-2389.2010.00485. $x$

Latham, G. P., \& Sue-Chan, C. (1999). A meta-analysis of the situational interview: An enumerative review of reasons for its validity. Canadian Psychology, 40, 56-67. doi:10.1037/ h0086826

Lee, K., \& Ashton, M. C. (2004). Psychometric properties of the HEXACO Personality Inventory. Multivariate Behavioral Research, 39, 329-358. doi:10.1207/s15327906mbr3902_8 
Levashina, J., Hartwell, C. J., Morgeson, F. P., \& Campion, M. A. (2014). The structured employment interview: Narrative and quantitative review of the research literature. Personnel Psychology, 67, 241-293. doi:10.1111/peps.12052

Lievens, F., \& De Paepe, A. (2004). An empirical investigation of interviewer-related factors that discourage the use of high structure interviews. Journal of Organizational Behavior, 25, 29-46. doi:10.1002/job.246

McCarthy, J. M., Van Iddekinge, C. H., \& Campion, M. A. (2010). Are highly structured job interviews resistant to demographic similarity effects? Personnel Psychology, 63, 325359. doi:10.1111/j.1744-6570.2010.01172.x

McCrae, R. R., Kurtz, J. E., Yamagata, S., \& Terracciano, A. (2011). Internal consistency, retest reliability, and their implications for personality scale validity. Personality and Social Psychology Review, 15, 28-50. doi:10.1177/1088868310366253

Motowidlo, S., J., Carter, G. W., Dunnette, M. D., Tippins, N., Warner, S., Burnett, J. R., \& Vaughan, M. J. (1992). Studies of the structured behavioral interview. Journal of Applied Psychology, 77, 571-587. doi:10.1037/0021-9010.77.5.571

Roulin, N., \& Bangerter, A. (2012). Understanding the academic-practitioner gap for structured interviews: "Behavioral" interviews diffuse, "structured" interviews do not. International Journal of Selection and Assessment, 20, 149-158. doi:10.1111/j.1468-2389.2012.00588.x

Ryan, A. M., McFarland, L., Baron, H., \& Page, R. (1999). An international look at selection practices: Nation and culture as explanations for variability in practice. Personnel Psychology, 52, 359-391. doi:10.1111/j.1744-6570.1999.tb00165.x

Rynes, S. L., Bartunek, J. M., \& Daft, R. L. (2001). Across the great divide: Knowledge creation and transfer between practitioners and academics. Academy of Management Journal, 44, 340-355. doi:10.5465/3069460

Terpstra, D. E., \& Rozell, E. J. (1997). Why some potentially effective staffing practices are seldom used. Public Personnel Management, 26. doi:10.1177/009102609702600405

Tonidandel, S., \& LeBreton, J. M. (2015). RWA Web: A free, comprehensive, web-based, and user-friendly tool for relative weight analyses. Journal of Business and Psychology, 30, 207-216. doi:10.1007/s10869-014-9351-Z

Tsai, W.-C., Chen, H. F., Chen, H.-Y., \& Tseng, K.-Y. (2016). When will interviewers be willing to use high-structured job interviews? The role of personality. International Journal of Selection and Assessment, 24, 92-105. doi:doi:10.1111/ ijsa.12133

van der Zee, K. I., Bakker, A. B., \& Bakker, P. (2002). Why are structured interviews so rarely used in personnel selection? Journal of Applied Psychology, 87, 176-184. doi: 10.1037/00219010.87.1.176

RECEIVED 02/20/19 ACCEPTED 05/22/19 
Appendix A

Full List of Interview Structure Items

Rapport building:

1. I ask questions to get to know the candidate as a person

2. I ask the candidate personal questions (about hobbies, etc.)

3. I begin the interview with light conversation

4. I try to start each interview by putting the interviewee at ease and building a strong rapport ${ }^{\text {a }}$

5. I spend time trying to connect with each applicant and understand who they are outside of the work context ${ }^{a}$ Question sophistication:

6. I use hypothetical or situational questions

7. I ask questions about how the candidate would go about performing a task

8. I use behavioral questions designed to get the candidate to relate specific accomplishments to the requirements of the job

9. I keep my questions general rather than overly specific (R)

Question consistency:

10. My questions are consistent across candidates

I1. I ask questions in the same order to every candidate

12. Questions are tailored to each candidate $(\mathrm{R})$

13. I have a list of questions I ask every candidate

14. I ask the same questions to each candidate

Probing:

15. I ask many prompting/follow up questions when I want to get "more" from a candidate on a question a

16. If a candidate doesn't answer a question fully, I will ask them for more information ${ }^{\mathrm{a}}$

Note taking:

17. I take detailed notes during the interview to help me make my evaluation ${ }^{a}$

Panel:

18. Today, interviews are conducted by... (one interviewer vs. two or more interviewers) ${ }^{a}$

Evaluation standardization:

19. I use a formal rating system that I apply to each candidate

20. I use anchored rating scales to evaluate the candidate's response to each question

21. I score the interview numerically in making an overall assessment

22. Decisions about the candidate are made by combining scores statistically, rather than making a global impression of their attractiveness

23. Each answer is rated against an ideal response

Note. ${ }^{\text {a }}$ Items added (i.e., not included in the final measure by Chapman \& Zweig, 2005) 
Appendix B

Correlations Between Facet-Level Personality and Structure Components Use

\begin{tabular}{|c|c|c|c|c|c|c|c|c|c|c|}
\hline & M & $\mathrm{SD}$ & $\begin{array}{l}\text { Rapport } \\
\text { building }\end{array}$ & $\begin{array}{c}\text { Question } \\
\text { sophistication }\end{array}$ & $\begin{array}{l}\text { Question } \\
\text { consistency }\end{array}$ & Probing & Note taking & Panel & $\begin{array}{c}\text { Evaluation } \\
\text { standardization }\end{array}$ & $\begin{array}{c}\text { Overall } \\
\text { Structure }\end{array}$ \\
\hline $\begin{array}{l}\text { Honesty-humility } \\
\text { sincerity }\end{array}$ & 3.59 & 0.99 & .05 & .00 & .09 & .13 & .05 & .00 & .04 & .01 \\
\hline $\begin{array}{l}\text { Honesty-humility } \\
\text { fairness }\end{array}$ & 4.74 & 0.62 & .04 & .13 & .01 & $.21 *$ & -.04 & -.05 & -.08 & -.08 \\
\hline $\begin{array}{l}\text { Honesty-humility } \\
\text { greed avoidance }\end{array}$ & 3.75 & 1.04 & .06 & .04 & .04 & -.09 & .10 & .05 & .02 & .08 \\
\hline $\begin{array}{l}\text { Honesty-humility } \\
\text { modesty }\end{array}$ & 4.24 & 0.82 & .01 & .07 & -.13 & .04 & -.04 & -.11 & .01 & -.10 \\
\hline $\begin{array}{l}\text { Emotionality } \\
\text { fearfulness }\end{array}$ & 2.79 & 1.08 & $-.19 *$ & .01 & .14 & -.14 & .15 & .11 & .01 & $.20^{*}$ \\
\hline Emotionality anxiety & 3.19 & 1.05 & -.08 & -.13 & .04 & -.09 & .12 & .00 & .02 & .06 \\
\hline $\begin{array}{l}\text { Emotionality } \\
\text { dependence }\end{array}$ & 2.05 & 0.59 & -.11 & -.04 & -.04 & -.06 & -.07 & .03 & .06 & .03 \\
\hline $\begin{array}{l}\text { Emotionality } \\
\text { sentimentality }\end{array}$ & 2.72 & 1.15 & -.12 & .00 & .08 & -.07 & .10 & .11 & .05 & .16 \\
\hline $\begin{array}{l}\text { Extraversion social } \\
\text { self-esteem }\end{array}$ & 4.63 & 0.52 & $.27 * *$ & -.03 & -.15 & .15 & -.11 & -.14 & -.12 & $-.26^{* *}$ \\
\hline $\begin{array}{l}\text { Extraversion social } \\
\text { boldness }\end{array}$ & 3.52 & 1.06 & .14 & -.10 & -.03 & $.17 *$ & -.01 & .00 & .02 & -.07 \\
\hline $\begin{array}{l}\text { Extraversion } \\
\text { sociability }\end{array}$ & 4.12 & 0.63 & $.26^{* *}$ & .01 & -.05 & $.21 *$ & $.19 *$ & -.12 & -.04 & -.11 \\
\hline Extraversion liveliness & 4.45 & 0.62 & $.28 * *$ & -.06 & -.05 & .14 & .10 & -.08 & .05 & -.10 \\
\hline $\begin{array}{l}\text { Agreeableness } \\
\text { forgiveness }\end{array}$ & 3.44 & 0.85 & $.19^{*}$ & -.11 & -.12 & -.03 & -.04 & .00 & -.06 & -.10 \\
\hline $\begin{array}{l}\text { Agreeableness } \\
\text { gentleness }\end{array}$ & 3.10 & 0.84 & -.04 & -.01 & .06 & -.11 & -.06 & -.01 & .08 & .03 \\
\hline $\begin{array}{l}\text { Agreeableness } \\
\text { flexibility }\end{array}$ & 2.88 & 0.74 & -.05 & .17 & .08 & -.07 & .02 & -.07 & .02 & .03 \\
\hline $\begin{array}{l}\text { Agreeableness } \\
\text { patience }\end{array}$ & 3.32 & 0.93 & .10 & .03 & $.18^{*}$ & .09 & .10 & .08 & .09 & .11 \\
\hline $\begin{array}{l}\text { Conscientiousness } \\
\text { organization }\end{array}$ & 3.89 & 0.80 & .02 & -.01 & .08 & -.04 & .10 & .15 & .15 & $.18^{*}$ \\
\hline $\begin{array}{l}\text { Conscientiousness } \\
\text { diligence }\end{array}$ & 3.62 & 0.84 & $.22 *$ & -.01 & -.01 & .04 & -.09 & .02 & .14 & -.02 \\
\hline $\begin{array}{l}\text { Conscientiousness } \\
\text { perfectionism }\end{array}$ & 3.76 & 0.72 & $.22 *$ & $.22 *$ & -.07 & $.22 *$ & -.11 & .07 & .09 & -.02 \\
\hline $\begin{array}{l}\text { Conscientiousness } \\
\text { prudence }\end{array}$ & 3.78 & 0.76 & -.06 & .05 & -.04 & .10 & -.04 & -.06 & .16 & -.01 \\
\hline $\begin{array}{l}\text { Openness aesthetic } \\
\text { appreciation }\end{array}$ & 2.84 & 1.02 & $.28 * *$ & -.03 & .08 & -.02 & .08 & .06 & $.19^{*}$ & .08 \\
\hline $\begin{array}{l}\text { Openness } \\
\text { inquisitiveness }\end{array}$ & 3.84 & 0.95 & .08 & .17 & .08 & .15 & $.34 * *$ & -.04 & .12 & .11 \\
\hline Openness creativity & 3.80 & 0.78 & .12 & .05 & -.01 & .02 & .12 & -.12 & .04 & -.04 \\
\hline $\begin{array}{l}\text { Openness } \\
\text { unconventionality }\end{array}$ & 3.33 & 0.75 & $.18^{*}$ & .03 & .02 & .15 & .15 & .09 & .06 & .07 \\
\hline
\end{tabular}

